\title{
Actualización sobre irrigantes y nuevas técnicas de irrigación utilizados para la elimi- nación del smear layer o barro dentinario.
}

Update on irrigants used

for the removal of smear layer.
Actualização sobre irrigantes utilizadas

para a remoção da camada de esfregaço.
Fecha de Recepción

10 de mayo de 2013
Aceptado para su publicación

18 de septiembre de 2013
Carlos Daniel Lugo De Langhe Becario de Perfeccionamiento tipo A SGCYT - FOUNNE. E-mail: lugocd@hotmail.con

María Teresa Rocha Auxiliar de la Cátedra de Endodoncia. Facultad de Odontología. UNNE. Av. Libertad 5450.

E-mail: trissirocha@yahoo.com.ar

Susana Beatriz Finten Titular de la Cátedra de Endodoncia. Facultad de Odontología. UNNE. Av. Libertad 5450. E-mail: susanafinten@yahoo.com.ar

\section{Resumen}

La irrigación hace necesario seleccionar sustancias que tengan la capacidad de eliminar tanto la porción orgánica como la inorgánica y cumplir una función de desinfección, lubricante, tener baja tensión superficial y no presentar efectos citotóxicos para los tejidos periapicales.

El objetivo de este trabajo es realizar una revisión en la literatura científica de los últimos años acerca de los diferentes irrigantes disponibles para la terapia endodóntica.

El hipoclorito de sodio es la sustancia más comúnmente utilizada para la irrigación de los conductos radiculares, a pesar de esto es incapaz de disolver la sustancia inorgánica, es por ello que se recomienda su utilización en combinación con alguna sustancia quelante.

También existen otras sustancias muy utilizadas como ser: la solución de gluconato de clorhexidina, los detergentes también conocidos como tensioactivos, las nuevas soluciones activadas electroquímicamente (ECA), Agua de Ozono, la desinfección por fotoactivación.

Hasta el momento no existe un irrigante ideal que utilizado de manera individual cumpla con todas las propiedades y sobre todo que sea capaz de eliminar esa capa residual de barro dentinario, por lo que en la actualidad se decide combinar soluciones para poder cumplir los objetivos necesarios. 


\section{Palabras Claves}

Hipoclorito de sodio, Quelantes, gluconato de clorhexidina.

\section{Abstract}

Irrigation makes necessary to select substances which have the ability to remove organic and inorganic substances and fulfill the function of disinfection, lubricant, have low surface tension and have no cytotoxic effects to periapical tissues.

The aim of this paper is to review the scientific literature in recent years about the different available irrigants for endodontic therapy.

Sodium hypochlorite is the most common substance used for irrigation of canal roots, although it is unable to dissolve the inorganic substance, which is why it is recommended for use in combination with a chelating agent.

There are also widely used substances such as: the chlorhexidine gluconate solution, detergents also known as surfactants, new solutions electrochemically activated (ECA), ozone water, disinfection by photoactivation.

So far there is no ideal irrigant that used individually meet all the properties and especially to be able to remove the residual smear layer, so now it is better to combine solutions in order to meet the required objectives.

\section{Key words}

Sodium hypochlorite, chelating, chlorhexidine gluconate.

\section{Resumo}

A irrigação fais necessário seleccionar substâncias que tenham a capacidade para remover tanto a porçãó orgânica como a inorgânica, e cumprir função de lubrificante, desinfecção, ter baixa tensão superficial e não ter efeitos citotóxicos para os tecidos periapicais.

O objetivo deste trabalho é revisar na literatura científica dos últimos anos sobre os irrigantes diferentes para terapia endodôntica disponível.

O hipoclorito de sódio é a substância mais utilizada para a irrigação de canais radiculares, embora ele não é capaz de dissolver a substância inorgânica, é por isso que se recomenda a utili- zação em combinação com um agente quelante.

Existem também substâncias amplamente utilizadas, tais como: a solução de gluconato de clorexidina, detergentes também conhecidos como surfactantes, novas soluções electroquimicamente activadas (ECA), água de ozono, desinfecção por fotoactivação.

Até agora não há irrigante ideal que usado individualmente atenda com todas as propriedades, especialmente, para ser capaz de remover a camada de magma residual, pelo que na atualidade se decide combinar soluções, a fim de cumprir com os objectivos necessários.

\section{Palavras chaves}

O hipoclorito de sódio, quelante, gluconato de clorexidina.

\section{Introducción}

La terapia endodóntica consiste en la eliminación completa de la pulpa que ha sufrido un daño irreversible y de todo el tejido remanente mediante los procedimientos de limpieza, conformación y obturación del sistema del conducto radicular, de manera que se pueda conservar el diente como una unidad funcional dentro del arco dental'.

En este proceso, se utilizan instrumentos endodónticos y soluciones químicas auxiliares para la irrigación, lo cual hace necesario seleccionar sustancias que tengan la capacidad de eliminar tanto las sustancias orgánicas como las inorgánicas y que cumplan una función de desinfección. Éstos son requisitos de una sustancia irrigadora ideal además de ser lubricante, tener baja tensión superficial y no presentar efectos citotóxicos para los tejidos periapicales ${ }^{2}$.

Durante la limpieza y conformación del conducto, se generan restos orgánicos (pulpa y predentina) y restos inorgánicos (limallas dentinarias), que se depositan sobre las paredes del conducto y forman una capa de barro dentinario (BD) o smear layer ${ }^{3}$. En conductos infectados pueden encontrarse también microorganismos. La utilización de las soluciones irrigadoras es importante para la eliminación de los mismos sobre todo en la luz del conducto radicular, pero su acción es limitada frente a los que se encuentran en los túbulos dentinarios, ramificaciones u otras áreas inaccesibles, pudiendo proliferar o reinfec- 
REVISTA FACULTAD DE ODONTOLOGÍA

ISSN No 1668-7280 - Vol. VI № 2 - 2013

64
DIVULGACION

Lugo De Langue - Rocha - Finten tar el sistema de conductos radiculares ${ }^{4}$.

El smear layer está químicamente formado por dos fases: la primera orgánica, compuesta por residuos de colágenos dentinarios y glicosaminoglicanos y que sirve de base a la segunda fase que es predominantemente inorgánica y que está compuesta por dos capas distintas y superpuestas; la primera delgada no adherente y fácil de remover que cubre las paredes de los conductos, y la segunda que ocluye los túbulos y se adhiere fuertemente a las paredes del conducto ${ }^{5}$.

La tendencia actual considera remover el barrillo dentinario, con el fin de lograr reducir el número de microorganismos que puedan estar presentes en él 6, eliminar los restos orgánicos que sirven de sustrato para el crecimiento y desarrollo bacteriano, aumentar la permeabilidad dentinaria optimizando la desinfección del conducto al permitir una mejor acción del irrigante y de la medicación tópica ${ }^{7,8}$.

Para eliminar esta capa de residuos el operador utiliza la irrigación, que es un proceso que consiste en el lavado y aspiración de todos los restos y sustancias que pueden estar contenidas dentro del sistema de conductos y se lleva a cabo mediante el uso de agentes químicos aislados o combinados durante la instrumentación del conducto radicular. Además, es el último procedimiento que se lleva a cabo antes de realizar la obturación tridimensional de los mismos?.

Se ha demostrado que las sustancias irrigadoras no remueven el contenido inorgánico adosado a las paredes, por lo que se ha visto la necesidad de utilizar sustancias quelantes que tengan la capacidad de atrapar los iones inorgánicos, con el fin de obtener un sistema de conductos adecuadamente limpio que pueda estar en contacto íntimo con el material de obturación.

El hipoclorito de sodio es la sustancia proteolítica más comúnmente utilizada para la irrigación de los conductos radiculares, debido a sus excelentes propiedades. A pesar de esto es incapaz de disolver la sustancia inorgánica que se encuentra en el barro dentinario, dificultando de esta manera su eliminación. Es por ello que se recomienda su utilización en combinación con alguna sustancia quelante, de las cuales, una de la más utilizadas es el ácido etilendiaminotetraacético (EDTA) al $17 \%{ }^{10}$.
El objetivo de este trabajo es realizar una revisión en la literatura científica de los últimos años acerca de los diferentes irrigantes disponibles para la terapia endodóntica; sus características, propiedades y mecanismos de acción, con el fin de contribuir al discernimiento para la elección del más apropiado o la mejor asociación de irrigantes para la eliminación del barro dentinario, y el que proporciona mejor desinfección durante la instrumentación del conducto radicular.

\section{Desarrollo}

La Asociación Americana de Endodoncistas define la irrigación como el lavado mediante una corriente de fluido. En endodoncia la irrigación intraconducto facilita la remoción física de materiales del interior de los conductos e introducción de químicos con actividad antimicrobiana, desmineralizante, disolvente del tejido, blanqueante, desodorante y para el control de la hemorragia" . Su principal objetivo la reducción de los microorganismos incluyendo aquellos difíciles de erradicar de los conductos radiculares, entre los cuales tenemos al Enterococcus faecalis, Actinomyces y Candida albicans ${ }^{12,13}$.

Aún no se hallo el irrigante ideal en endodoncia, que además de tener una actividad antimicrobiana, sea capaz de disolver material orgánico ayudando en el debridamiento mecánico, manteniendo las paredes del conducto hidratadas ejerciendo acción de lubricante y que sea lo menos irritante posible para los tejidos, reduciendo su toxicidad ${ }^{14-17}$. Otra característica importante que debería cumplir es la capacidad para eliminar el barro dentinario, a fin de dejar una superficie permeable que permita la difusión de la medicación intraconducto aumentando su área de acción, además de proporcionar un contacto más íntimo entre el material obturador y las paredes del conducto, mejorando su adhesión y sellamiento marginal.

Existen varios factores que influyen directamente en la permeabilidad dentinaria, el diámetro de los canalículos, la edad del paciente, la naturaleza química de los fármacos y por último, y no menos importante es el barro dentinario, formado por la acción del instrumento sobre las paredes del conducto, que al colocarse en la superficie del canal radicular principalmente en la 
región apical, obstruye las entradas de los túbulos alterando la permeabilidad dentinaria ${ }^{10}$.

Las soluciones de irrigación utilizadas son: el hipoclorito de sodio a diferentes concentraciones, los agentes quelantes solos o combinados, la clorhexidina, ácidos, peróxidos, detergentes.

Además se han desarrollando soluciones irrigadoras como MTADI8 (Biopure, Tulsa Denstply OK USA) y Tetraclean son nuevos productos que asocian sustancias para eliminar el smear layer con actividad antimicrobiana, Q-Mix ${ }^{19}$, soluciones electroquímicamente activas 20 , fotoactivación ${ }^{21}$, agua ozonada ${ }^{20,22}$ e irrigación ultrasónica pasiva ${ }^{23}$.

La Asociación Americana de Endodoncistas ha definido al hipoclorito de sodio $(\mathrm{NaOCl})$ como un liquido claro, pálido, verde - amarillento, extremadamente alcalino y con fuerte olor clorino, que presenta una acción disolvente sobre el tejido necrótico y restos orgánicos y además es un potente agente antimicrobiano?.

Es un compuesto químico resultante de la mezcla de cloro, hidróxido de sodio y agua. Fue desarrollado por el francés Bertholleten 1787 para blanquear telas. Luego a fines del siglo XIX Luis Pasteur comprobó su poder de desinfección, extendiendo su uso en defensa de la salud contra gérmenes y bacterias. Su amplia utilización en endodoncia se debe a su capacidad para disolver tejidos y a su acción antibacteriana ${ }^{24}$.

El hipoclorito de sodio pertenece al grupo de los compuestos halogenados. En odontología se comenzó a utilizar hacia el año 1792, cuando fue producido por primera vez y recibió el nombre de Agua de Javele.

Lo podemos clasificar en 25

$\mathrm{NaOCl}$ al $5 \%$ (soda clorada)

$\mathrm{NaOCl}$ al 2,5\% (solución de Labarraque)

$\mathrm{NaOCl}$ al $1 \%$ con $16 \%$ de cloruro de sodio (solución de Milton)

$\mathrm{NaOCl}$ al 0,5\% con acido bórico para reducir el ph (solución de Dakin)

$\mathrm{NaOCl}$ al $0,5 \%$ con bicarbonato de sodio (solución de Dausfrene)

El Hipoclorito de Sodio logra efectivos resultados en la remoción del tejido pulpar. Por el contrario su acción sobre el tejido inorgánico ha mostrado ser poco convincente.

La acción del $\mathrm{NaOCl}$ se ve influenciada por factores como la temperatura, dilución, grados de pureza, la frecuencia, volumen del irrigante:

Temperatura: Su aumento incrementa el efecto disolvente sobre los tejidos. El aumento de la temperatura del Hipoclorito de sodio, aumenta el efecto bactericida, la capacidad disolvente del tejido y mejora el desbridamiento sin afectar la estabilidad química de la solución, aunque sólo se mantiene estable por 4 horas $^{26}$.

Dilución: Mientras mayor sea su concentración mayor será su acción antimicrobiana, la propiedad de disolución del tejido y la propiedad de desbridamiento del sistema de conductos.

Grados de pureza: Una de las mayores preocupaciones en relación al $\mathrm{NaOCl}$ se refiere a su inestabilidad química. Las soluciones disponibles comercialmente presentan generalmente concentraciones disminuidas con respecto de la especificación de los fabricantes.

La frecuencia de la irrigación y el volumen del irrigante son muy importantes en la remoción de los restos. A mayor volumen e irrigaciones más frecuentes se aumenta la efectividad.

A medida que la preparación se acerca a la constricción apical, se requiere que el irrigante esté por lo menos a I $\circ 2 \mathrm{~mm}$ del ápice, 27.

Se denominan quelantes a las sustancias que tienen la propiedad de fijar los iones metálicos en un determinado complejo molecular. El término quelar es derivado del griego "Khele" que significa garra.

La quelación es un fenómeno físico-químico por el cual ciertos iones metálicos son retirados de los complejos de los que hacen parte, sin constituir una unión química con la sustancia quelante y sin ninguna combinación. Este proceso es repetido hasta acabar la acción quelante y por eso no es efectuado por el mecanismo de disolución ${ }^{27}$.

Son sustancias que se utilizan como auxiliares de la preparación biomecánica, sobre todo en conductos atrésicos o calcificados. Se cree que son inocuos para los tejidos apicales y periapicales $^{28,29}$.

Son agentes quelantes el ácido etilendiamino tetraacético (EDTA), el ácido cítrico, ácido poliacrílico, ácido maleico entre otros.

El ácido etilendiaminotetraacético (EDTA) fue el primer agente quelante descrito para el uso en endodoncia por Nygaard Östby en 1957. Se utiliza como sal disódica o trisódica del EDTA. 
Es un quelante específico para el ion calcio y por consiguiente para la dentina. Es una sustancia fluida con un $\mathrm{pH}$ neutro de $\mathrm{de}^{7,3}$. Se emplea en una concentración del 10 al $17 \%$. Con esta solución se logra reducir a siete el grado de dureza Knoop de la dentina, que normalmente tiene una dureza de cuarenta y dos cerca de la luz del conducto no tratado. Además es usado para lubricación, emulsificación y para mantener las virutas dentinarias en suspensión.

Se le atribuye un cierto efecto antibacterial sobre ciertas especies bacterianas como Streptococcus alfahemolíticos y Staphylococcus aureus, $y$ un alto efecto antimicótico. Produce una reacción inflamatoria leve al contacto con tejido blando, al contacto con tejido óseo reacciona en forma similar al de la dentina ${ }^{8}$. No es tóxico y menos irritante en soluciones débiles.

Su mecanismo de acción se basa en una reacción química entre el agente quelante y los iones metálicos de los cristales de hidroxiapatita con la producción de un quelato metálico; el cual reacciona con las terminaciones del agente quelante al remover los iones de calcio de la dentina que se reblandece, cambiando las características de solubilidad y permeabilidad del tejido especialmente la dentina peritubular rica en hidroxiapatita, incrementando el diámetro de los túbulos dentinales expuestos. El quelante también tiene una gran afinidad por los álcalis ferrosos de la estructura dental ${ }^{28}$.

El EDTA remueve efectivamente el barro dentinario en I minuto, si el fluido alcanza correctamente la superficie de las paredes dentinarias y después de I minuto de exposición sobre la dentina, comienza a afectar la estructura dentinaria ${ }^{29}$.

El efecto de los agentes quelantes ha sido evaluado mediante una variedad de métodos tales como microscopia electrónica, medidas de microdureza y microradiográficamente, donde se analizó la eficiencia de estos agentes en la remoción del smear-layer, la desmineralización y ablandamiento de la dentina radicular ${ }^{30}$.

Dogan y Yamada ${ }^{31,} 32$ afirman que durante $y$ después de la instrumentación es necesario usar agentes quelantes, seguido por algún solvente de tejido. Así, en la actualidad es ampliamente aceptado que el método más efectivo para remover los componentes orgánicos e inorgánicos del lodo dentinario es irrigar el conducto con EDTA seguido por $\mathrm{NaOCl}$ para obtener túbulos dentinarios y conductos accesorios limpios y permeables que permitan una mejor adhesión y adaptación de los materiales de obturación en las paredes

dentinarias, propiciando así un sellado hermético y por ende el éxito del tratamiento de conductos.

Semra y cols $^{33}$ aconsejan una irrigación de los conductos con $10 \mathrm{ml}$ de EDTA del 15 al $17 \%$ seguido por $10 \mathrm{ml}$ de hipoclorito de sodio del 2,5 al $5,25 \%$ durante I minuto. Con esta combinación, se ha encontrado que el efecto del quelante es mayor a nivel cervical y medio de la raíz, pero es deficiente en el tercio apical ${ }^{34}$. La utilización del EDTA durante 3 minutos continuos elimina la capa residual de las paredes del conducto radicular ${ }^{35}$ y si se utiliza EDTA al $17 \%$ con ultrasonido es eficaz para quitar el barro dentinario en la región apical de la raíz ${ }^{36}$.

La irrigación final con EDTA al 17\%, seguida de $\mathrm{NaOCl}$ al $5.25 \%$, resulta en una mezcla sinérgica que disminuye la tensión superficial, permitiendo la difusión facilitada del $\mathrm{NaOCl}$ para obtener una efectiva acción quelante sobre la hidroxiapatita de los túbulos dentinarios ${ }^{37,38}$.

Comercialmente se los conoce como EDTA o EGTA, el RC-prep, EDTAC, y GLYDE, FILEEZE.

El Rc-Prep, fue desarrollado en 1969 por Stewart, es una combinación de EDTA al 15\% con peróxido de urea y glicol 10\%; presenta consistencia jabonosa. La urea es un compuesto aminado que forma solventes en forma de ureato de calcio cuando reaccionan con los iones de calcio quelados por el EDTA, lo que aumenta de permeabilidad de la dentina.

De acuerdo a las investigaciones de Heling ${ }^{39}$ el peróxido de urea al $10 \%$ es un ingrediente activo que produce radicales hidroxilos que oxidan los grupos sulfidrilos, las cadenas dobles proteicas, los lípidos y la pared celular bacteriana, causando muerte celular.

Es decir tiene una acción antiséptica y la interacción del peróxido de urea con el hipoclorito produce una acción burbujeante que libera y arrastra los residuos dentinarios. El tamaño de las burbujas resultante de esta combinación es más pequeño que las producidas por la asocia- 
ción del hipoclorito con el peróxido de hidrógeno, siendo más fácil su posterior aspiración ${ }^{40}$.

Sin embargo, Verdelis y cols. ${ }^{30}$, demostraron que el RC-Prep no tiene la capacidad de remover por completo la capa de barrillo dentinario, debido a su bajo $\mathrm{pH}$.

Es de interés lo hallado por Morris y cols. que se refieren al uso combinado del hipoclorito con el RC-Prep que disminuye significativamente la capacidad de adhesión de los cementos a base de resinas a las superficies endodónticamente tratadas ${ }^{4 l}$.

EI EDTAC es la sal disódica del ácido etilendiaminotetraacético con cetavlón o bromuro de cetil-trimetil-amonio o cetrimida. Se utiliza en una concentración al $15 \%$ y tiene un $\mathrm{pH}$ de 7,3 a 7,4. El cetavlón posee acción antibacteriana y reduce la tensión superficial de la dentina, lo que provoca el aumento de la capacidad de penetración del hipoclorito de sodio cuando ambas soluciones se utilizan combinadas (EDTA y $\mathrm{NaOCL}$ ). Es una asociación muy efectiva para la eliminación del barrillo dentinario.

Yamaguchi y cols. $^{42}$, en 1996 propusieron la solución acuosa de ácido cítrico como agente de irrigación en el tratamiento del sistema de conductos. Se puede utilizar solo o combinado con EDTA. Algunos autores consideran que es un agente muy conveniente debido a su bajo costo, buena estabilidad química si es usado correctamente alternándolo con $\mathrm{NaOCl}$, y con mayor capacidad antibacteriana y quelante que el EDTA ${ }^{28,29}$.

Sceiza y cols..$^{43}$ determinaron que el EDTA-T y el ácido cítrico al 10\%, usados como irrigantes endodónticos hacían más visibles los túbulos dentinarios que el hipoclorito de sodio al $5 \%$ asociado al peróxido de hidrógeno al 3\%, y asimismo, que el ácido cítrico fue más biocompatible con los tejidos periodontales apicales que el EDTA-T.

El ácido poliacrilíco y el ácido maleico al 7\% también pueden ser utilizados para eliminar el barro dentinario. 44

EI MTAD fue desarrollado por $M$. Torabinejad ${ }^{45}$ para el retiro del smear layer con propiedad antimicrobiana, es una mezcla de $3 \%$ doxyclina; 4,25\% de ácido cítrico y detergente Tween 80 y aconseja su uso como irrigación final después del empleo de $\mathrm{NaOCl}^{46}$.
Otro irrigante recientemente desarrollado en Canadá es el Q- Mix por el Dr Marcus Haapasalo y cols, que lo recomiendan como irrigación final para remover el smear layer y biofilm persistente. Contiene EDTA, Clorhexidina y Cetrimide mezclada con agua destilada con adición de sal ${ }^{47}$.

La solución de gluconato de clorhexidina se utilizó por primera vez en Gran Bretaña en 1954, como antiséptico para heridas de piel, y en Odontología en 1959 se usó para la desinfección de la cavidad oral; $y$ a partir de 1970 gracias a los estudios realizados por Loe y Schiott se popularizó el uso de la clorhexidina como enjuague bucal capaz de inhibir la neoformación de placa y el desarrollo de la gingivitis ${ }^{40}$.

Su mecanismo de acción es el resultado de la absorción de clorhexidina dentro de la pared celular de los microorganismos produciendo filtración de los componentes intracelulares; también daña las barreras de permeabilidad en la pared celular, originando trastornos metabólicos de las bacterias. Otra de sus acciones consiste en la precipitación proteica en el citoplasma bacteriano, inactivando sus procesos reproductivos $y$ vitales $^{40,48,49}$.

Algunos autores la han propuesto como irrigante de conductos radiculares por su acción bactericida, compatibilidad y por su liberación gradual prolongada; y como medicamento intraconducto ${ }^{48,50,51}$.

Se utiliza en concentraciones de $0,12 \circ 2 \%{ }^{48}$ tiene baja toxicidad y su actividad antimicrobiana in vitro fue encontrada equivalente al del hipoclorito de sodio al $5,25 \%$, sin embargo no tiene capacidad para disolver material orgánico ${ }^{52}$. Es activo contra bacterias Gram-positivas y Gramnegativas comúnmente encontrados en las infecciones endodónticas, aerobios y anaerobios facultativos, y hongos o levaduras.

El gel de clorhexidina y las soluciones líquidas de $0,2 \%$, $1 \%$ y $2 \%$ fueron comparadas con el $\mathrm{NaOCl}$ al $0,5 \%, 1 \%, 2,5 \%, 4 \%$ y al $5,25 \%$ y se concluyó que la solución de clorhexidina al $2 \%$ elimina tanto S. Aureus como Cándida Álbicans en 15 segundos y el gel de clorhexidina elimina los microorganismos E. faecalis en I minuto y porphyromonas, en 15 segundos $^{52,53}$.

La clorhexidina tiene la propiedad de sustantibilidad, por sus cargas catiónicas se une a 
la hidroxiapatita de la dentina ${ }^{54}$, desde allí actúa como un reservorio, liberándose en forma gradual y progresiva.

Mientras la clorhexidina puede espontáneamente hidrolizarse a Paracloramine (PCA) con el tiempo, pero también al combinarse con $\mathrm{NaOCl}$ sufre una reacción química y forma un precipitado que contiene PCA que es una amina aromática. Si se irriga con agua para eliminar el $\mathrm{NaOCl}$ del canal antes de que clorhexidina sea usada, así se reduce al mínimo la formación de PCA. La irrigación con clorhexidina y EDTA no causa reacción química ${ }^{55}$.

Los detergentes también conocidos como tensioactivos. Su uso está indicado exclusivamente en dientes con pulpa vital donde se observó criterios rigurosos de antisepsia y asepsia ${ }^{56}$. Se clasifican en detergentes aniónicos (carga negativa por ejemplo lauril sulfato de sodio), catiónicos (carga positiva ej. cetavlón) o neutros (sin carga ej Tween 80 ) dependiendo de la polarización que presente la molécula. Los detergentes que posen carga son por lo general más eficaces debido a la formación de una interfase con la misma carga entre la superficie y el residuo, haciendo que se rechacen las cargas del mismo signo, las partículas englobadas no consiguen depositarse nuevamente ${ }^{57}$

Las nuevas soluciones activadas electroquímicamente (ECA) ○ Agua Superoxidizada o agua con potencial oxidativo: son generadas por electrólisis de una solución salina, un proceso que no es diferente al utilizado en la producción comercial de hipoclorito de sodio $^{58}$, y cuyas propiedades dependen de la fuerza de la solución salina inicial, la diferencia de potencial aplicado y el tipo de generación. La tecnología que permite la recolección de las respectivas soluciones reside en el diseño del ánodo y el cátodo y se origina tanto en Rusia (electroquímicamente agua activada) ${ }^{59} \mathrm{O}$ Japón (agua potencial oxidativo) ${ }^{29,60}$.

Aunque las soluciones se denominan de manera diferente, los principios de fabricación, son probablemente los mismos, son prácticamente inocuas para los tejidos biológicos, y tienen actividad antimicrobiana ${ }^{61}$. En la actualidad las investigaciones acerca del uso de esta tecnología son aún escasas.

Las soluciones de ambas tecnologías han sido probadas por su capacidad de desbridamiento de los conductos radiculares ${ }^{59,60,62}$ eliminar la capa de barro dentinario $0^{29,60}$ matar las bacterias ${ }^{63}$ y las esporas bacterianas, ${ }^{64}$ con resultados favorables, además muestra biocompatibilidad con los sistemas vitales ${ }^{65}$

Marais ${ }^{59}$ en su estudio, comparó los efectos de limpieza del hipoclorito de sodio con el agua activada electroquímicamente en las paredes del sistema de conductos radiculares, concluyendo que esta última produjo superficies más limpias que el hipoclorito, y que removió grandes áreas de capa de desechos, por lo el ECA fue considerada superior al hipoclorito.

Hata y cols. ${ }^{60}$ Solovyeva y cols. ${ }^{62}$ realizaron estudios, donde evaluaron la capacidad de estas soluciones en la remoción de barro dentinario y sobre el acondicionamiento final de la dentina sugiriendo que las soluciones electrolíticamente activadas son tan eficaz como el hipoclorito de sodio al $5 \%$ o el EDTA al $17 \%$ para abrir y dejar permeables los túbulos dentinarios.

Dependiendo del tipo ECA, el pH varía; este puede ser ácido, neutro o alcalino; el pH ácido fue usado al principio pero en los últimos años han recomendado a las soluciones neutras y alcalinas para el uso clínico ${ }^{58}$.

Agua de Ozono: El ozono es uno de los agentes antimicrobianos más poderosos disponibles para el empleo en la medicina y la odontología. El ozono es una molécula compuesta por tres átomos de oxígeno, se genera a partir del aire u oxígeno aplicando una descarga de alto voltaje. El gas "ozonizado" se mezcla con el agua para disolverse. La desinfección más eficiente se logra con $0.4 \mathrm{mg} / \mathrm{l}$ sostenido por 4 minutos, es decir un CT (Concentración en $\mathrm{mg} / \mathrm{l}$ por Tiempo en minutos) de I.6. La cantidad de ozono requerido para alcanzar estos valores de CT depende de la temperatura del agua, del $\mathrm{pH}$, de la demanda inicial de ozono y el sistema de contacto. Por lo regular, esta cantidad suele ser entre 1 y 2 $\mathrm{mg} / \mathrm{l}$ de dosificación de ozono al agua. Nagayoshi y cols $^{66}$ han propuesto al ozono como un agente dental antiséptico basado en los informes de sus efectos antimicrobianos tanto en formas gaseosas como en acuosas. Es un agente poderoso anti microbiano contra bacterias, hongos, protozoarios y virus. El Ozono es eficaz cuando es prescrito en la concentración suficiente, usado durante un tiempo adecuado, $y$ entregado 
REVISTA FACULTAD DE ODONTOLOGÍA

ISSN No 1668-7280 - Vol. VI № 2 - 2013

69
DIVULGACION

Actualización sobre irrigantes y nuevas

técnicas de irrigación utilizados para

la eliminación del smear layer o barro dentinario. correctamente en los CR después de que la limpieza y conformación han sido completadas. El líquido debería ser agitado con el ultrasonido. El ozono es un tratamiento eficaz, fácil, barato, y rápido para ayudar desinfectar $\mathrm{CR}$. Es el más poderoso antimicrobiano y oxidante que podemos usar en endodoncia ${ }^{58}$.

La desinfección por fotoactivación es una nueva tecnología que puede ser una alternativa menos tóxica que las soluciones irrigadoras químicas. Utiliza una combinación de una infiltración fotosensibilizante y una luz con longitud de onda específico. Esta combinación elimina una gran población de bacterias en suspensiones plactónicas, colágeno y dentina infectada. También se muestra efectiva contra bacterias comúnmente encontradas en los conductos radiculares ${ }^{67}$.

La búsqueda de una solución irrigadora ideal continúa con el desarrollo de investigaciones de nuevas sustancias.68 Todavía existe un gran interés científico permanente en buscar sustancias más eficaces, con acción bactericida más potente, rápida y de mejor comportamiento biológico con los tejidos perirradiculares ${ }^{69}$.

Como así también aparecieron nuevos sistemas de irrigación y/o desinfección de los CR, entre ellos el sistema endoactivador (Dentsply Tulsa Dental Specialties) que utiliza una punta de polímero no cortante en una pieza de mano, que según Desai $^{70}$ tiene la ventaja que produce un mínimo de extrusión del irrigante al comparar con la irrigación manual, ultrasónica y el sistema rinse endo.

La irrigación ultrasónica pasiva se basa en la transmisión de energía acústica desde una lima oscilante o alambre liso a una solución de irrigación previamente depositada en el CR, debido a la transmisión activa de la irrigación su potencial de contacto con una mayor superficie se verá incrementada. Es decir el término pasivo no describe adecuadamente el proceso ya que el mismo es activo, sólo se lo debe relacionar con la acción no cortante de la lima activada ultrasónicamente. Recientemente se están comercializando, alambres lisos montados en un dispositivo de ultrasonido. Sin embargo, en este momento no se pueden dar directivas claras en cuanto a su relación riesgo/beneficio ${ }^{71}$.

\section{Conclusiones}

La irrigación es un procedimiento imprescindible en el proceso de limpieza y conformación del sistema de conductos, favorece las necesidades biológicas del diente, definiendo las condiciones óptimas para la obturación.

La efectividad de un método de irrigación directamente relacionada con la capacidad de remoción del tejido orgánico e inorgánico, la frecuencia, volumen empleado, temperatura y la cercanía a la constricción apical. Hasta el momento no existe un irrigante ideal que utilizado de manera individual cumpla con todas las propiedades y sobre todo sea capaz de eliminar esa capa residual de barro dentinario, por lo que en la actualidad se decide combinar soluciones para poder cumplir los objetivos necesarios.

La remoción del barro dentinario es una condición indispensable para lograr el éxito en la terapéutica, ya que su presencia constituye un obstáculo para la penetración del cemento sellador en los túbulos dentinarios.

Las soluciones activadas electrolíticamente son una alternativa al hipoclorito de sodio en el tratamiento de conductos convencional, pero es necesario realizar más investigaciones sobre el tema.

Para la elección de la solución irrigadora en la terapia endodóntica se deben tener en cuenta factores como la acción antimicrobiana, disolvente y toxicidad. 


\section{Bibliografía}

I. Pérez E., Burguera E., Carvallo M. Tríada para la limpieza y conformación del sistema de conductos radiculares. Acta Odontol. Venez. 2003; 4I (2): I59-165.

2. Zenhder M. Root canal Irrigants. J Endod. 2006; 32 (5): 389-98.

3. Mc Comb D, Smith DC. A preliminary scanning electron microscopic study of root canals after endodontic procedures. J Endod. 1975; I (7): 238-242.

4. Sassone IM, Fidel R, Vieria M, Hirata Júnior R. The influence of organic load on the antimicrobial activity of different concentrations of $\mathrm{NaOCl}$ and chorhexidine in vitro. Int Endodod J. 2003; 36 (I2): 848-52.

5. Manzur Conte A J, Castilla Arroyo G, Andrade L M, et al. Influencia de dos geles de clorhexidina en la remoción del barro dentinario. Acta odontol. Venez. 2005; 43 (2): II9-124.

6. Di Lenarda $R$, Cadenaro M, Sbaizero O. Effectiveness of I mol L-I citric acid and I5\% EDTA irrigation on smear layer removal. Int Endod J. 2000; 33: 46-52.

7. Hülsmann M, Heckendorff M, lennon A. Chelanting agents in root canal treatment: mode of action and indications for their use. Int Endod J. 2003; 36: 810-830.

8. Torabinejad M, Cho Y, Khademi AA, Bakland K, Shabahang S. Efecto de diferentes concentraciones de hipoclorito sódico sobre la capacidad de eliminación del barrillo dentinario del MTAD. Rev Esp Endod. 2003; 21 (3): 179-190.

9. Lahoud Salem V, Galvéz Calla L H. Irrigación endodontica con el usos de hipoclorito de sodio. Odontol. Sanmarquina. 2006; 9 (I): 28-30.

10. Himel V T, Mcspadden Jt, Goodis H E. Instrumentos, Materiales y Dispositivos. En: Cohen S, Hargreaves K M. Vias de la Pulpa. 9 ed. Madrid: Elsevier; 2008. P. 239-295.

II. Pineda Vélez E, Gil Pulgarin N, Pérez Guizao M. Comparacion del efecto in vitro del etilendiaminotetracetico (EDTA) en la eliminación del barrillo dentinario, utilizando una marca comercial y un producto genérico. Revista Nal de Odontologia. Indd. 2010; 6 (10): 18-25.

12. Bergenholtz G, Spanberg L. Controversies in endodontics. Crit Rev Oral Biol med. 2004; I5: 99.

13. Haapasalo M, Udnaes T, Endal U. Persistent, recurrent, and acquired infection of the root canal system post-treatment. Endodon Topics. 2004; 6: 29.

14. Carson KR,. Goodell G, Scott B. McClanahan. Comparison of the Antimicrobial Activity of Six Irrigants on Primary Endodontic Pathogens. J Endod. 2005; 3 I (6): 47I-73.

15. Boutsioukis C, Lambrianidis T, Kastrinakis E. Irrigant flow within a prepared root canal using various flow rates: a Computational Fluid Dynamics study. Int.Endod J. 2009; 42: I44-I55.

16. Menezes MM, Valera MC, Mancini MNG. In vitro evaluation of the effectiveness of irrigants and intracanal medicaments on microorganisms within root Canals. Int. Endod J. 2004; 37: 3I I-I9.

17. Estrela C, Estrela CRA, Barbin EL, Spano JC, Marchesan M, Pecora JD. Mechanism of action of sodium hypochlorite. Braz dent J. 2002; 13 (2): II3-II7.

18. Torabinejad M,Handysides R,Khademi AA, Bakland LK. Clinical implications of the smear layer in endodontics: a review. Oral Surg Oral Med Oral Pathol Oral Radiol Endodon. 2002; 94: 658.

19. Meana Kumari C, Sandya Kapoor Punia, Vikas Punia. Root Ca- nal Irrigants and Irrigation Techniques- A Review Part I. Indian Journal of Dental Sciences. 2012; vol 4 (3): 91-94.

20. El Karim I, Kennedy J, Hussey D. The antimicrobial effects of root canal irrigation and mediacation. Oral Surg Oral Med Oral pathol oral Radiol Endod. 2007; 103 (4): 560-9.

21. Williams JA, Pearson GJ, Wilson M, John CM. Anti bacterial action of photoacti vated disinfection (PAD) used on endodontic bacteria in planktonic suspension and in artificial and human root canals. J Dent. 2006; 34 (6): 363-7I.

22. Cậmara Andréa C, Muniz de Albuquerque M, Menezes Aguiar C. Soluções Irrigadoras Utilizadas para o Preparo Biomecânico de Canais Radiculares.Pesq Bras Odontoped Clin Integr, João Pessoa. 2010; 10 (I): 127-I33.

23. Van der Sluis L, Wu Min-Kai, Wessenlink P. Comparación de dos métodos de lavado empleados en la irrigación ultrasónica pasiva de los conductos radiculares. Quintessence. 20I I; 24 (2): $8 \mathrm{I}-5$.

24. Balandrano Pinal F. Soluciones para irrigación en endodoncia: hipoclorito de sodio y gluconato de clorhexidina. Revista CCDCR. 2007; 3 (I): II-I4.

25. Pecora J D, Estrela C. Hipoclorito de Sodio. En: Hecht M, editor. Ciencia Endodontica. I ed. Sau Paulo: Artes Medicas Ltda; 2005. P. 4I5-455.

26. Olmos Fassi J, Carril M A, Seguir S, García Rusco A. Limpieza de las paredes del conducto usando una combinación de hipoclorito de sodio $2,5 \%$ - acido cítrico $10 \%$ y clorhexidina $2 \%$ _ acido cítrico 10\%. Endodoncia. 2009; 27 (2): 63-67.

27. Teixeira K I R, Cortes M E. Estado actual de la indicación de antimicrobianos para la medicación intracanal. Acta odontol. Venez. 2005; 43 (2): I77-I80.

28. Calt S., Serper A. Efectos del EDTA que dependen del tiempo en la estructura dentinaria. J Endod. 2002; 28: 17-19.

29. Serper A., Calt S. Efectos desmineralizantes del EDTA en diferentes concentraciones y pH. J Endod. 2002; 28: 50I-02.

30. Verdelis K, Eliades G, Oviir T, Mergelos J. Effect of chelating agents on the molecular composition and extent of decalcification at cervical, middle and apical root dentin locations. Endod Dent Traumat. 1999; 15: 164-70.

31. Dogan H, Calt S. Effects of chelating agents and sodium hypochlorite on mineral content of root dentin. J Endod. 200 ; 27 (9): 578-80.

32. Fróes JA, Horta HG, da Silveira $A B$. Smear layer infl uence on the apical seal of tour different obturation technique. J Endod. 2000; 26 (6): 35I-4.

33. Semra C, Ahmet S. Time-dependent effects of EDTA on dentin structures. J Endodon. 2002; 28 (I): 17-19.

34. Estrela C. Ciencia Endodóntica. São-Paulo, Brasil: Ed. Artes Médicas Latinoamericana; 2005.

35. Mellol, KammererBA, Yoshimoto D. Influence of final rinse technique on ability of ethylene diamine tetra acetic acid of removing smear layer. J Endo. 2010; 36: 5I2-4.

36. Kuah HG, Lui JN, Tseng PS, Chen NN. The effect of ETA with and without ultra sonics on removal of the smear layer. IEJ. 2010; 43: $31-40$.

37. González PG, Liñán FM, Ortiz VM, Ortiz VG, Del Real LA Guerrero-Lara G. Estudio comparativo in vitro de tres acondicionadores de dentina para evaluar apertura de los túbulos dentina- 
REVISTA FACULTAD DE ODONTOLOGÍA

ISSN No 1668-7280 - Vol. VI No 2 - 2013

71
DIVULGACION

Actualización sobre irrigantes y nuevas técnicas de irrigación utilizados para la eliminación del smear layer o barro dentinario. rios en conductos radiculares. Revista Odontológica Mexicana. 2009; 13 (4): 217-233.

38. Gu XH, Mao CY, Kern M. Effect of different irrigation on smear layer removal after post space prepration. J Endo. 2009; 35: 3936.

39. Heling I., Iraní E., Karni S., and Steimberg D. "In vitro antimicrobial effect of Rc-Prep within dentinal tubules". J. Endod. 1999; 25: 782-5.

40. Ingle II, Backland LK. Endodoncia. $4^{\mathrm{a} E d i c i o ́ n . ~ M e x i c o: ~ E d i t . ~}$ McGraw-Hill Interamericana; 2000. 98-237.

4I. Morris M. D., Lee K. W., Agee K. A., Bouillaget S and Pashley $\mathrm{D} \mathrm{H}$. "Effects of sodium hypochlorite and RC-Prep on bond strengths of resin cements to endodontic surfaces". J. Endod. 200I; 27 (I2): 753-7.

42. Yamaguchi M, Yoshida K, Suzuki R, and Nakamura H. "Root canal irrigation with citric acid solution". J. Endod. 1996; 22(I): 27-29.

43. Sceiza M. F., Daniel R. L., Santos E. M. and Jaeger M. M. "Cytotoxic effects of $10 \%$ citric acid and EDTA-T used as root canal irrigants: an in vitro analysis". J. Endod. 200I; 27(I2): 74I-3.

44. Ballal NV, KadianS, MalaK, Bhat.KS. Comparison of the efficacy of maleic acid and EDTA in smear layer removal from instrumented human root canal-A scaning electroninc microscopic study. J. Endod. 2009; 35: 1573-6.

45. Torabinejad M, Khademi A A, Babagoli J, Cho Y, Johnson WB, Bozhihov $K$ et al. A new solution for the removal of smear layer. J. Endod 2003; 29: 170-5

46. Torabinejad M, Cho Y, Khademi A A, Shabahang S. The effect of various concentrations of sodium hypochlorite on the ability of MTAD to remove the smear layer. J. Endod-2003; 29: 233-9.

47. M D Linx, Dai $L$ et al. The Effect of QMix, an Experimental Antibacterial Root Canal Irrigant, on Removal of Canal Wall Smear Layer and Debris. JOE. 20I I; 37 (I): 80-4.

48. Morgana E, Gomes FA, Zaia A.F. In vitro evaluation of the antimicrobial activity of chlorhexidine and sodium hypochlorite. Oral Surg Oral Med Oral Pathol Oral Radiol Endod. 2004; 97: 79-84.

49. Yamashita J, Tanomaru M, Leonardo M. Scaning electron microscopic study of the cleaning ability of chlorhexidine as a rootcanal irrigant. Int Endod J. 2003; 36: 391-94.

50. Cohen. Burns R. Vias de la pulpa. $8^{\mathrm{a}}$ ed. Madrid España: Elsevier; 2001.

5I. Ching S, Wang. Clinical efficiency of 2\% chlorhexidine gel in reducing intracanal bacteria. J. Endod. 2007; 33 (II): 1283-89.

52. Gomes B P, Ferraz C C, Vianna M E, Berber V B, Teixeira F $B$ and Souza-Filho $F \mathrm{~J}$. "In vitro antimicrobial activity of several concentrations of sodium hypochlorite and chlorhexidine gluconato in the elimination of Enterococcus faecalis". Int. Endod. J. 200 I; 34(6): 424.

53. Vianna ME, Gomes BP, Berber VB, Zaia AA, Ferraz C.C, De Souza FilhoFJ. In vitro evaluation of the antimicrobial activity of chlorhexidine and sodium hypo chlorite. Oral Surg, Oral Med, Oral Path, Oral Radio, Endod. 2004; 97: 79-84.

54. Schäfer E, Bössmann K Antimicrobial efficacy of chlorhexidine and two calcium hydroxide formulations against Enterococcus faecalis. J Endod. 2005; 3I (I): 53-56.

55. Meena kumari C, Sandya Kapoor Punia, Vikas Punia. Root Canal Irrigants And Irrigation Techniques. A Review Part IIndian
Journal of Dental Sciences. 2012; 4(3): 091-094.

56. Pécora JD, Souza-Neto MD, Estrela C. Soluções auxiliares do preparo do canal radicular. En: Estrela C, Figueiredo JAP. Endodontia: princípios biológicos e mecânicos. São Paulo: Artes Médicas, 200I. p. 553-69. 7.

57. Souza ADS, Machado MEL, Massaro H. Substâncias químicas auxiliares utilizadas em endodonti a-irrigação e aspiração. En: Machado MEL. Endodonti a: da biologia à técnica. São Paulo: Santos, 2007. p. 253-67.

58. Frais $\mathrm{S}, \mathrm{Ng} \mathrm{Y}-\mathrm{L}$, and Gulabivala $\mathrm{K}$. "Some factors affecting the concentration of available chlorine in comercial sources of sodium hypochlorite". Int. Endod. J. 200I; 34: 206.

59. Marais, JT. "Cleaning efficacy of a new root canal irrigation solution: a preliminary evaluation”. Int. Endod. J. 2000; 33 (4): 320.

60. Hata G, Hayami S, Weine F. S. and Toda T. "Effectiveness of oxidative potential water as a root canal irrigant". Int. Endod. J. 200I; 34 (4): 308.

6I. 6I) Gulabivala K, Stock CJ, Lewsey JD, Ghori S, Ng YL, Spratt DA. Effectiveness Of Electrochemically Activated Water As An Irrigant In An Infected Tooth Model. Int Endod J. 2004; 37: 624.

62. Gulabivala K, Stock CJ, Lewsey JD, Ghori S, Ng YL, Spratt DA. Effectiveness Of Electrochemically Activated Water As An Irrigant In An Infected Tooth Model. Int Endod J. 2004; 37: 624.

63. Solovyeva AM, Dummer PMH. Cleaning Effectiveness Of Root Canal Irrigation With Electrochemically Activated Anolyte And Catholyte Solutions: A Pilot Study. Int Endod J. 2000; 33: 494.

64. Horiba N, Hiratsuka K, Onoe T Et Al., Bactericidal Effect Of Electrolysed Neutral Water On Bacteria Isolated From Infected Root Canals. Oral Surg, Oral Med, Oral Pathol, Oral Radiol, Endod. 1999; 87:83.

65. Loshon CA, Melly E, Setlow B, Setlow P Analysis Of The Killing Of Spores Of Bacillus Subtilis By A New Disinfectant, Sterilox®. J Applied Microbiology 200I; 9I: 105.

66. Ichikawa K, Nakamura HK, Ogawa N, Sakimura T, Kuroda M. R\&D Of Long-Term Life-Support System By Using Electrochemically Activated Biofilm Reactor Of Aquatic Animals For Space Examinations. Biological Science In Space 1999; 13: 348.

67. Nagayoshi M, Kitamur a C, Fukuizumi T, et al. Antimicrobial effect of ozonated water on bacteria invading dentinal tubules. J Endod. 2004; 30: 778-8I.

68. Williams JA, Pearson G], Wilson M, John CM. Anti bacterial acti on of photoacti vated disinfecti on (PAD) used on endodontic bacteria in planktonic suspension and in artificial and human root canals. J Dent. 2006; 34 (6): 363-7I.

69. Cruz Câmara A, Muniz de Albuquerque M, Menezes Aguiar C. Soluções Irrigadoras Utilizadas para o Preparo Biomecânico de Canais Radiculares. Pesq Bras Odontoped Clin Integr, João Pessoa 2010; 10 (I): I27-133.

70. Ortega Cruz Hernán F. Bonetti Filho I.López Ampuero, Brenda P. Evaluación "in vitro" de la asociación del efecto antimicrobiano del unido a vehículos y medicamentos de acción prolongada. Acta Odontológica Venezolana . 2008; 46 (2): I-9

71. Desai P, Himel V. Comparative Safety Of Various Intracanal Irrigation Systems. J Endod. 2009; 35: 545.

72. Zehnder M. Root Canal Irrigants. Review, J Endod. 2006; 32: 389-98. 